\title{
An independent learning manual to support clinical reasoning and facilitate reflection in early physiotherapy student placements: a case study
}

\author{
Benjamin K. Weeks', Megan Dalton ${ }^{2}$ \\ ${ }^{1}$ School of Rehabilitation Sciences, Centre for Musculoskeletal Research, Gold Coast campus, Griffith University, Queensland, Australia \\ ${ }^{2}$ School of Primary Health Care, Faculty of Medicine Nursing and Health Sciences, Monash University, Victoria, Australia
}

\section{Email address:}

b.weeks@griffith.edu.au (B. K. Weeks)

\section{To cite this article}

Benjamin K. Weeks, Megan Dalton. An Independent Learning Manual to Support Clinical Reasoning and Facilitate Reflection in Early Physiotherapy Student Placements: A Case Study. Education Journal. Vol. 2, No. 2, 2013, pp.58-63. doi: 10.11648/j.edu.20130202.15

\begin{abstract}
In response to student feedback and in line with the concept of 'guided discovery learning', we designed an independent learning manual (ILM) to support students over the course of their first major clinical placement. In particular, the ILM was introduced to facilitate the development of clinical reasoning skills, and encourage independent learning and self-reflection. The manual was issued to students in the first year of the physiotherapy program at Griffith University in 2009 and to all associated clinical educators. Student and educator satisfaction of the ILM was determined by survey, while student performance was determined by clinical placement grades and compared to that of the previous cohort unsupported by the ILM. Students rated the ILM as an effective resource $(5.0 \pm 0.8$ on 7 -point scale, $n=49)$ and educators rated the ILM as very effective ( $4.1 \pm 0.4$ on 5-point scale, $\mathrm{n}=7$ ). Further, clinical placement grades were greater for students issued with the ILM compared to students without the ILM $(82.8 \pm 9.5$ vs. $77.7 \pm 10.7, p=0.01)$. In all, we found that a new resource to support physiotherapy students in an orthopaedic clinical placement was well-received by students and educators and resulted in higher clinical placement grades in comparison to the previous year.
\end{abstract}

Keywords: Clinical Education; Clinical Reasoning; Independent Learning; Orthopaedics; Physical Therapy; Self - Directed Learning

\section{Introduction}

Workplace-based learning and assessment is an essential component of physiotherapy and other health professional education programs. It provides opportunities for students to apply theoretical knowledge in a work place context and fosters the necessary professional skills and attributes required for practice [1-2]. Physiotherapy students at Griffith University attend a number of compulsory clinical placements integrated throughout their academic program. The placements provide work-based experience in all core areas of physiotherapy practice beginning with a two-week introductory placement in an aged care setting. The second placement is the first 'major' hospital-based placement for students where they are expected to manage a case load of patients in the area of inpatient orthopaedics. Subsequent placements are held in the musculoskeletal, cardiorespiratory, neurological and paediatric areas. The learning objectives of each placement are closely aligned with the profes- sional requirements of the accrediting body, the Australian Physiotherapy Council and as such, encourage students to demonstrate knowledge and skill akin to a new graduate physiotherapist. Accordingly, students must begin the challenging transition from 'university student' to 'clinician' [3-4]. The second clinical placement (i.e. orthopaedics), where students are first asked to begin this transition is embedded in the final weeks of the first semester.

Student evaluations in 2008 identified a need for 'more concrete' guidance during their orthopaedic clinical placement. Informal student feedback suggested that the situation was unfamiliar to them and that they were unsure of how to maximise their learning and complete the unit successfully. Clinical educator feedback echoed the need for more tangible guidance for students on placement and suggestions were made for a book of guidelines or a checklist. Further, while on placement students frequently experience short periods of 'down time' where educators are busy with administrative commitments or there are no suitable patients for treatment - a time when they might benefit from 
engaging in independent or self-directed learning activities. Based on this feedback a decision was made to develop a self-directed learning resource that would not only provide students with a 'checklist' of things they should cover whilst on placement, but also help them to adjust to the clinical environment and adopt the role of clinician.

An overarching goal of the clinical placement, and the whole physiotherapy program, is to assist students to develop the ability to learn independently providing the skills essential for successful lifelong learning. Encouraging students to 'learn how to learn' is recognised as an important strategy to facilitate future engagement in professional development and maintain professional (and clinical) competency [5]. With these intentions, a manual was developed to serve as an introduction to independent learning methods on placement and a catalyst for learning in subsequent clinical placements and professional practice.

The aim of this project was to develop a student independent learning manual (ILM) for the first major hospital placement and evaluate student and educator satisfaction of the ILM, and student clinical performance. A secondary aim of the project was to identify shortcomings of the ILM that could be addressed to improve it for future editions.

\section{Method}

\subsection{ILM Development}

To facilitate ongoing engagement with theory-based content presented during the on-campus part of the semester and guidance throughout the clinical placement, a student ILM was developed. Specifically, the ILM is a resource designed to assist students in preparing, familiarising, revising, and engaging with the theoretical content and practical skills they have covered during the teaching semester and to encourage self-evaluation and reflection of their clinical practice throughout the unit. To this aim, the ILM is organised into three time periods: before, during, and after the clinical placement. This approach facilitates preparation for the unit, assists learning during the unit, and promotes reflection once the unit has been completed. The information in the ILM is evidence-based and provides links to the relevant research sources. Use of the manual in combination with the clinical placement and traditional learning activities parallels characteristics of 'guided-discovery learning' [6]. This learning approach demands clear learning objectives, a manual to guide and focus learning in combination with traditional learning activities, such as lectures and practicals/placements [7]. Prior to its issue to students, a draft copy of the ILM was reviewed by members of the Queensland Orthopaedic Physiotherapy Network (QOPN), the Senior Lecturer in Clinical Education at Griffith University, and physiotherapy Clinical Educators at QEII Hospital. After feedback from all parties was collated and used to make further inclusions and refinements to the manual, it was issued to students partaking their placement in 2009.

\subsection{ILM Evaluation}

The ILM was formally evaluated using several approaches and involved collecting feedback from students $(n=55)$, clinical educators $(n=7)$, and industry experts (i.e. the QOPN). Students in their first year of the Master of Physiotherapy program (2009) at Griffith University were issued the manual to support their orthopaedic clinical placement. Student satisfaction of the manual was determined from an item on an anonymous student evaluation (i.e. "How effective were the supporting resources used in this course in helping you learn?") and student email testimonials, whilst anonymous feedback from clinical educators was collected via a customised survey inclusive of ten closed questions with responses made on a 5-point Likert scale and two open questions requesting written response (Table 1). All clinical educators surveyed had a minimum of three years of clinical experience. ILMs were also sent to members of the QOPN and the Chair of the network collected written feedback and forwarded it to the investigator via email.

\section{Table 1. Survey of clinical educator satisfaction of the ILM.}

Responses made on a 5 -point Likert scale $(1=$ strongly disagree to $5=$ strongly agree):

1. The purpose of the independent learning manual was clear.

2. The manual was easy to navigate (i.e. table of contents, page numbers etc.)

3. The content and activities in the manual are relevant to the student's involvement and experiences in clinical unit 2 orthopaedics.

4. The manual effectively encourages independent learning

5. The manual effectively promotes clinical reasoning.

6. The clinical cases in the manual were realistic and appropriate to the student's involvement in clinical unit 2 orthopaedics.

7. The manual helps reinforce important aspects of safety in orthopaedics.

8. The manual is effective in encouraging self-reflection of clinical practice.

9. The manual should be used again for future students undertaking clinical unit 2 orthopaedics

10. Overall, the manual is an effective inclusion to the orthopaedic clinical unit.

\section{Open questions:}

11. What are the best aspects of the learning manual (i.e. what should be kept)?

12. What aspects of the learning manual are lacking (i.e. are there things you would like to see extended or added to the manual in future)?

The ILM was provided to students undertaking their clinical placements in 2009 and was evaluated on completion of the placement by students and educators to determine its effectiveness and facilitate future modifications. Student performance was evaluated using clinical placement marks 
and compared to student performance in the previous year.

\subsection{Analyses}

Mean scores from survey items were calculated along with percentage positive and negative responses. Responses to open questions were themed and considered individually. An independent samples t-test was performed using SPSS v.19 (IBM, Chicago, USA) to compare clinical placement marks in 2008 and 2009 with a p-value of less than or equal to 0.05 used to determine statistical significance.

\section{Results}

\subsection{ILM Specifications and Inclusions}

The ILM is 53 pages in total including a contents page, preface and overview, and three major sections (or chapters). In the first section, Before the Placement, activities focus on goal setting for the placement and general preparation. For example, the third question in this section asks 'Think about what experiences you would like to gain from this particular placement. Describe some strategies you can use to maximise your learning'. Students are also asked to reflect on their performance and feedback from their last on-campus practical examination (i.e. an orthopaedic viva) and to highlight how they will address identified shortcomings. The last important part of this section is safety, highlighting and reinforcing common safety concerns in orthopaedic physiotherapy.

The second section, During the Placement, includes activities to help orientate students to the hospital and ward, questions relating to basic competencies and prioritising patients, types of orthopaedic conditions and repair approaches, assessment and treatment procedures, clinical case studies, and a learning contract for use in mid-unit feedback. These activities are focused on issues that have been previously identified by clinical educators as essential learning.

The third and final section, After the Placement, is designed to encourage reflective practice. In order to align and integrate reflective practice into the course design, we introduced a reflective practice assignment to the clinical placement and embedded it in the ILM and course assessment. The use of reflective practice in clinical practice and discussion of examples of clinical practice were given in class time and the guidelines for the assignment were included toward the end of the ILM.

\subsection{Student Satisfaction}

Overall, $89 \%(49 / 55)$ of students in the course completed the course evaluation and rated the ILM as an effective resource (mean score of 5.0 on a 7-point Likert scale) (Table 2). Comments received from student emails were mainly positive. Those not seen as positive were in fact not negative, but rather constructive. Positive student comments included:

'I really liked that it [the ILM] outlined the common concepts to know so it tested us before we went out [on placement] and shows the educators our baseline'

'Case studies were good, very realistic to the type of cases we were exposed to'

'The sections with lists of abbreviations and medications were excellent - it gave us some focus during self-directed learning time on placement. It was also really good because once it was completed it is a reference that can be kept beyond this placement'

'The section about prioritising is fantastic. A lot of the time we had no idea about planning how to prioritise treatment, so it was great to be able to discuss this with other students on placement and compare how we would go about it'

Constructive student comments included:

'Perhaps at the beginning outline a list of people in the multidisciplinary team and when they should be contacted when certain issues arise - especially the medical team (such as the Resident, Registrar, Consultant etc.)'

'In lectures and on placement we were regularly exposed to multi-stage hip and knee replacements/revisions post infection etc. It would be valuable to include these types of surgeries and their weight-bearing status, protocols etc. in the check list in Section 1'

'Perhaps this section [i.e. During the Placement] could be altered to include something like what information would be expected to go under the following chart headings: subjective examination, objective examination, treatment'

Table 2. Responses to student evaluation item $(n=49)$.

\begin{tabular}{lllll}
\hline Survey item & $\begin{array}{l}\text { Response } \\
(\%)\end{array}$ & Mean \pm SD & Range & $\begin{array}{l}\text { Positive } \\
(\%)\end{array}$ \\
\hline $\begin{array}{l}\text { 1. How effective } \\
\text { were the supporting } \\
\text { resources used in } \\
\text { this course in } \\
\text { helping you learn? }\end{array}$ & 89.1 & $5.0 \pm 0.8$ & $4.0-7.0$ & 85 \\
\hline
\end{tabular}

Key: SD, standard deviation.

\subsection{Clinical Educator Satisfaction}

Overall, clinical educators rated the manual as an effective resource (mean score of 4.1 on a 5-point scale) (Table 3 ). Several responses were made to open questions. In response to the first open question (i.e. What are the best aspects of the learning manual?), five positive statements were fielded including:

'All good'

'All excellent'

'The manual reinforces expectations of knowledge'

'All aspects are useful and should be retained'

'All fine'

Three constructive comments were fielded for the second open question (i.e. What aspects of the learning manual are lacking?) including:

'Some tasks in section two should be done earlier before commencement of the clinical placement' 
'Students need some feedback as to whether their answers are correct or complete'

'A standard example of a chart entry is lacking'

Several positive comments were fielded by email from educators and members of the QOPN. One educator commented that: 'The new orthopaedic independent learning manual for students is a great idea. Students at this stage need this to keep them focused on the important things and help them adequately reflect'. Similarly, another educator stated that 'it [the ILM] is a valuable tool to guide students through their placements'. Further recommendations received from QOPN members during feedback collection related to: increasing reference to surgical patients; updating and including several medications in the medication review section; and including more clinical case scenarios to challenge students' prioritisation skills.

Table 3. Clinical educator satisfaction of the ILM $(n=7)$.

\begin{tabular}{|c|c|c|c|c|}
\hline Survey Item & Response (\%) & Mean \pm SD & Range & Positive (\%) \\
\hline 1. The purpose of the independent learning manual was clear. & 100 & $4.3 \pm 0.5$ & $4.0-5.0$ & 100 \\
\hline 2. The manual was easy to navigate (i.e. contents, page numbers, etc.). & 100 & $4.3 \pm 0.5$ & $4.0-5.0$ & 100 \\
\hline $\begin{array}{l}\text { 3. The content and activities in the manual are relevant to the student's in- } \\
\text { volvement and experiences in clinical unit } 2 \text { orthopaedics. }\end{array}$ & -100 & $4.4 \pm 0.5$ & $4.0-5.0$ & 100 \\
\hline 4. The manual effectively encourages independent learning. & 100 & $4.0 \pm 0.6$ & $3.0-5.0$ & 86 \\
\hline 5. The manual effectively promotes clinical reasoning. & 100 & $4.0 \pm 0.6$ & $3.0-5.0$ & 86 \\
\hline $\begin{array}{l}\text { 6. The clinical cases in the manual were realistic and appropriate to the stu- } \\
\text { dent's involvement in clinical unit } 2 \text { orthopaedics. }\end{array}$ & 100 & $4.1 \pm 0.4$ & $4.0-5.0$ & 100 \\
\hline 7. The manual helps reinforce important aspects of safety in orthopaedics. & 100 & $4.1 \pm 0.4$ & $4.0-5.0$ & 100 \\
\hline 8. The manual is effective in encouraging self-reflection of clinical practice. & 100 & $3.9 \pm 0.7$ & $3.0-5.0$ & 71 \\
\hline $\begin{array}{l}\text { 9. The manual should be used again for future students undertaking clinical } \\
\text { unit } 2 \text { orthopaedics. }\end{array}$ & 100 & $4.4 \pm 0.5$ & $4.0-5.0$ & 100 \\
\hline $\begin{array}{l}\text { 10. Overall, the manual is an effective inclusion to the orthopaedic clinical } \\
\text { unit. }\end{array}$ & 100 & $4.1 \pm 0.4$ & $4.0-5.0$ & 100 \\
\hline
\end{tabular}

Key: SD, standard deviation.

\subsection{Student Performance}

Student summative assessment scores for students in 2009 who received the ILM were higher were than those for the previous cohort in 2008 who did not receive the $\operatorname{ILM}(82.8 \pm 9.5$ vs. $77.7 \pm 10.7 ; \mathrm{p}=0.01)$ (Figure 1).

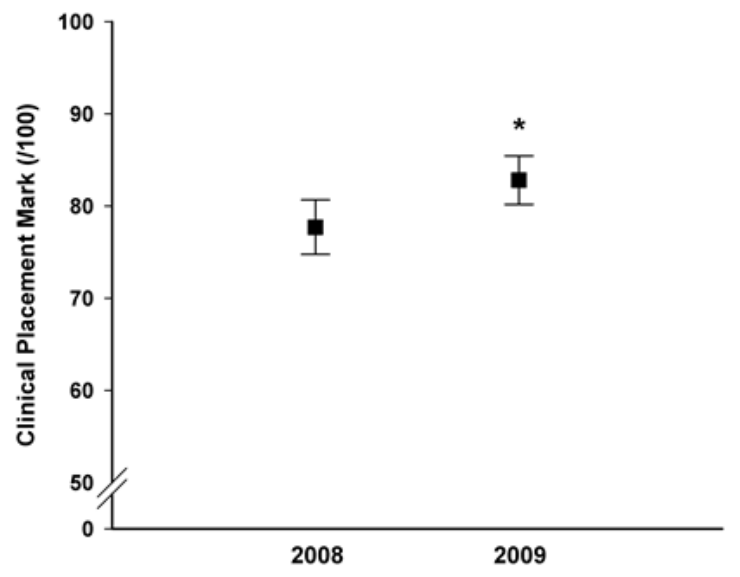

Figure 1. Student clinical placement marks (mean $\pm 95 \%$ CI) for Unit 2 Orthopaedics in $2008(n=50)$ and $2009(n=55)$.

*, significant between-group difference, $p<0.05$.

\section{Discussion}

The primary aim of the project was to develop and im- plement an independent learning manual (ILM) to support early physiotherapy students in their first major hospital placement and evaluate student and educator satisfaction of the ILM, and student clinical performance. Once consensus was reached between staff, educators, and industry professionals on the necessary inclusions in the ILM, it was issued to students in 2009 prior to their orthopaedic clinical placement.

All outcomes of satisfaction and performance were positive. Students were highly satisfied with the effectiveness of the ILM for their learning and a range of positive comments were received. Likewise, clinical educators were highly satisfied with the effectiveness of the ILM and no negative ratings were received for any survey items. Unanimous educator support was received for continued issue of the ILM for future student cohorts. Furthermore, students supported by the ILM in 2009 performed better on their orthopaedic clinical placement than the previous cohort in 2008 who were not supported by the ILM. It is important to note that this improvement could however be due to factors other than the introduction of the ILM, e.g., the 2009 cohort of students were higher performing students than those of 2008, or overall the clinical educators in 2008 assessed more harshly than those of 2009.

A secondary aim of the project was to identify shortcomings of the ILM that could be addressed to drive enhancements for future editions. Despite a very positive reception from students and educators, constructive feedback 
on how to improve the manual was also forthcoming. For instance, student recommendations were for inclusion of a list of professionals in a multidisciplinary team, additional surgical conditions, and a section on record keeping in orthopaedics. The latter was also recommended by a clinical educator. Further, educators suggested that greater feedback to students on their answers to ILM questions was warranted. In response to this feedback these suggestions have been included in the current edition of the ILM.

Independent learning is an important generic skill for physiotherapy graduates. Encouraging students to 'learn how to learn' is important to facilitate future engagement with their own professional development and maintain professional (and clinical) competency [5]. Accordingly, activities in the ILM were constructed in such a way that they would support the clinical activities undertaken by the students as they progressed through the placement. For example, students on orthopaedic clinical placement are expected to have knowledge of the most prevalent surgical protocols for common elective procedures. Thus, several activities in Section 2 ask the student to revise, make notes, and prioritise patient cases around procedures such as hip replacements, knee replacements, and intervertebral disc replacements.

The ILM and the activities contained within it were designed to align with course objectives and professional accreditation standards. Constructive alignment such as this is considered critical to student learning [8-9]. Further, it is recognised that students better retain knowledge when they have experienced relevance in the learning process; the more episodically-rich activities they engage in, the more likely they will develop semantic representations and know rather than just remember [10]. Thus, the activities of the ILM were structured to parallel their clinical activities on the ward.

A particular focus of the ILM was reflective practice - an essential attribute of graduate physiotherapists. It is suggested that reflection may improve students' ability to culminate information and form associations that lead to deeper and more positive learning experiences [11]. More specifically, critical analysis of clinical performance may aid in the identification of effective and ineffective practices and be catalytic for improved clinical practice. Further, critical reflection is regarded as an effective strategy to achieve the broad objectives of work-based learning [12-13], and has been shown to be directly linked to the development of professional expertise [14]. In an effort to emphasise the importance of reflective practice, the ILM incorporated instructions for a reflective practice assessment task that required students to document their reflections on patient cases each week of their placement and comment on what they believe they did well and what they thought they could improve.

Inclusion of a learning contract complemented the ILM learning activities and reflective practice tasks. Students are able to complete the learning contract in consultation with their educator in order to identify their shortcomings in a timely manner and devise a strategy for improvement. For example, when faced with their end-of-unit mark, students will sometimes attest that they were not aware of the things they were not doing well at the time or that they were not aware of how they could improve. The inclusion of a learning contract in the ILM is an effort to alleviate these issues. It is a method of 'negotiated feedback' [15], which is very specific to the student and involves discussion of the objectives, strategies, how the student will provide evidence of their learning and the timeline in which improvement is to be achieved.

In summary, students and educators were satisfied with the introduction of a new ILM for an early physiotherapy clinical placement in the orthopaedic setting. Further, clinical performance of students supported by the ILM was better than students in the previous year who were not issued an ILM. Overall student and educator impressions indicated that the ILM was an effective resource to support student clinical education and its' inclusion should be maintained for future clinical placements. In line with continuous quality improvement, the ILM will continue to be evaluated and modified based on feedback from all relevant stakeholders.

\section{Acknowledgements}

The authors would like to acknowledge contributions by Mr Michael Bourke for his input in the initial development of the ILM, and Mrs Wendy Harris for her administrative support in the evaluation phase of the project.

\section{References}

[1] Wass, V., Van der Vleuten, C., Shatzer, J., and Jones, R. Assessment of clinical competence. Lancet, 2001. 357(9260): p. 945-9.

[2] Dean, C.M., Stark, A.M., Gates, C.A., Czerniec, S.A., Hobbs, C.L., Bullock, L.D. and Kolodziej, I. A profile of physiotherapy clinical education. Australian Health Review, 2009. 33(1): p. 38-46.

[3] Adam, K., Peters, S. and Chipchase, L. Knowledge, skills and professional behaviours required by occupational therapist and physiotherapist beginning practitioners in work-related practice: A systematic review. Australian Occupational Therapy Journal, 2013. 60: p.76-84.

[4] May, W.W., Morgan, B.J., Lemke, J.C., Karst, G.M. and Stone, H.L. Model for ability-based assessment in physical therapy education. Journal of Physical Therapy Education, 1995. 9: p. 3-6.

[5] Neame, R.L. and Powis, D.A. Toward independent learning: Curricular design for assisting students to learn how to learn. Journal of Medical Education, 1981. 56(11): p. 886-93.

[6] Harden, R.M., Davis, M.H. and Crosby, J.R. The new Dundee medical curriculum: a whole that is greater than the sum of its parts. Medical Education, 1997. 31: p. 264-71.

[7] Spencer, J.A. and Jordan, R.K. Learner centred approaches in medical education. British Medical Journal, 1999. 318: p. 
$1280-3$.

[8] Biggs, J. Enhancing teaching through constructive alignment. Higher Education, 1996. 32(3): p. 347-64.

[9] Wang, X., Su, Y., Cheung, S., Wong, E. and Kwong, T. An exploration of Biggs' constructive alignment in course design and its impact on students' learning approaches. Assessment \& Evaluation in Higher Education, 2012. DOI:10.1080/02602938.2012.658018

[10] Herbert, D.M.B. and Burt, J.S. What do students remember? Episodic memory and the development of schematization. Applied Cognitive Psychology, 2004. 18: p. 77-88.

[11] Sobral, D. Mindset for reflective learning: A revalidation of the reflection in learning scale. Advances in Health Sciences Education, 2005. 10: p. 303-314.
[12] Boud, D. Creating a work based curriculum. Work-based learning: A new higher education, ed. D. Boud and P. Solomon. 2001, Buckingham, UK: Open University Press \& Society for Research into Higher Education.

[13] Lester, S. and Costley, C. Work-based learning at higher education level: Value, practice and critique. Studies in Higher Education, 2010. 35: p.561-575.

[14] Edwards, I., Jones, M., Carr, J., Braunack-Mayer, A. and Jensen, G.M. Clinical reasoning strategies in physical therapy. Physical Therapy, 2004. 84: p.312-330.

[15] Boud, D., Cohen, R. and Sampson, J.K. Peer learning and assessment. Assessment and Evaluation in Higher Education, 1999. 24: p.413-426. 